\title{
Upper Limb Congenital Anomalies in Nigeria
}

David Odoyoh Odatuwa-Omagbemi, ${ }^{1}$ Emeka Izuagba, ${ }^{2}$ Roy Efetobor Enemudo, ${ }^{1}$ Taiwo Olusola Osisanya, ${ }^{3}$ Cletus Ikechukwu Otene, ${ }^{1}$ Lukman Olalekan Ajiboye ${ }^{4}$

1. Department of Surgery, Delta State University, Abraka, Nigeria

2. Department of Orthopedics and Traumatology, National Orthopedic Hospital, Lagos, Nigeria

3. Department of Plastic and Reconstructive Surgery, National Orthopedic Hospital, Lagos, Nigeria

4. Department of Orthopedics and Traumatology, Usman Danfodiyo University Teaching Hospital, Sokoto Nigeria

Correspondence to: Dr. David Odoyoh Odatuwa-Omagbemi; email: odatuwa@live.com

\begin{abstract}
Background: About $1-2 \%$ of neonates have congenital anomalies; of these, $10 \%$ affect the upper limbs. Congenital anomalies are structural or metabolic defects present at birth. Objective: To review cases seen over a four-year period in a tertiary specialist hospital in Lagos and share our experience. Methodology: Case notes and theatre records of patients with congenital upper limb anomalies were retrieved and relevant data extracted. Data were analyzed with SPSS version 20. Results: 46 patients with 53 diagnoses of upper extremity congenital anomalies: 28 were males and 18 females between 5 weeks and 14 years. 17 patients $(37 \%)$ presented within the first 12 months of life. Average ages of mothers and fathers were 34.1 and 37 years respectively. $26 \%$ of mothers had febrile illnesses and $28.3 \%$ used herbal products during the index pregnancies. Swanson's group 2 was the commonest (58.4). Syndactyly was the
\end{abstract}

\section{Introduction}

Congenital anomalies or birth defects are structural or functional anomalies, including metabolic disorders, that are present at birth (1). About 1 to $2 \%$ of neonates are born with congenital anomalies; $10 \%$ of these anomalies affect the upper limbs $(2,3)$. One out of every 626 live births has congenital upper limb anomaly, in most cases minor without functional deficit, and only $10 \%$ of these will actually require treatment (4).

These anomalies may occur in isolation or may be associated with other systemic anomalies in the cardiovascular, neurologic, hematologic and other musculoskeletal systems, or might be part of a syndrome like Holt-Oram, Apert's and other associations. The upper limbs in humans start to develop at about the 4th week of intra-uterine life and commonest descriptive individual diagnosis (49\%). Treatments were individualized according to specific diagnosis. Conclusions: Congenital anomalies of the upper extremities present as various diagnostic entities. Syndactyly was the most frequently encountered here.

Keywords: Upper limbs, Congenital, Anomalies

Ann Afr Surg. 2020; 17(3):106-111

DOI: http://dx.doi.org/10.4314/aas.v17i3.4

Conflicts of Interest: None

Funding: None

(C) 2020 Author. This work is licensed under the Creative Commons Attribution 4.0 International License

Submitted: 15 March 2019

Revised: 21 December 2019

Accepted: 18 February 2020

Online first: 29 May 2020

are fully developed by the end of the 8th week of gestation. This development is under the control of three signaling centers: i) the apical ectodermal ridge that controls proximal to distal limb development by secreting fibroblast growth factor, ii) the zone of polarizing activity that controls radio-ulnar axis limb development by secreting Hedgehog protein, and iii) the wingless type signaling center that produces a molecule responsible for dorso-lateral development of the upper limbs (1,2,4-6). Abnormal happenings or disruptive activities at any of these signaling centers at the critical period of limb development will lead to various congenital upper limb anomalies (2).

In about $40-50 \%$ of cases, the etiology of congenital upper limb anomaly is unknown. Genetic and various 
environmental teratogenic factors have been implicated in the etiology of the rest $(1,4)$.

Congenital upper extremity anomalies when they occur are usually a source of worry to parents and care givers, and their fears need to be assuaged by the attending doctor. The surgeon should thoroughly evaluate cases in order to counsel the parents properly. In addition, congenital anomalies associated with other systemic problems will need further investigative work-ups and referrals/consultations to other specialists as some conditions may require more urgent attention than the obvious upper limb anomaly the child presents with $(1,7)$.

We review cases of congenital upper limb anomalies seen and managed in our center over a 4-year period and share our experiences.

\section{Materials and methods}

A 4-year retrospective review of cases of congenital upper limb anomalies seen at a tertiary specialist hospital in Lagos between January 2014 and December 2017. For the purpose of this study, congenital anomalies of the upper limbs in children are "structural or functional anomalies which are present at birth in children between ages $0-16$ years presenting to our health facility." Case notes and theatre records of patients who met the defined criteria during the study period of 48 months were retrieved from the records department and relevant information including biodata, antenatal and family history, diagnosis, investigations, treatments offered and outcome were extracted and entered into an already prepared proforma for that purpose. Case notes without complete records were left out.

Similar anomalies affecting both upper limbs were taken as a single diagnosis while significantly different anomalies affecting the two upper limbs were taken as separate diagnoses with regards to frequencies.

Swanson's classification $(8,9)$ was used to group cases into 7 sub-groups and individual descriptive diagnosis of cases and tabulations were done accordingly.

Data were analyzed using SPSS version 20 (SPSS Inc. Chicago, Illinois, USA) and presented in form of tables, ratios and percentages. Sample photographs of some cases (preoperative and postoperative) are also presented in the Results.

\section{Results}

Forty-six patients with 53 congenital upper limb anomalies were reviewed in 4-year period (January
2014 to December 2017). There were 28 males and 18 females, giving a male: female ratio of 1.56:1. Their ages at presentation ranged from 5 weeks to 14 years. Seventeen patients (37\%) presented within the first 12 months of life and another 11 (23\%) presented between 12 and 24 months of age (Table 1).

\begin{tabular}{cc}
\multicolumn{2}{c}{ Table 1. Age distribution of patients at presentation } \\
\hline Age group (months) & Frequency (\%) \\
\hline$<12$ & $17(37.0)$ \\
$12-24$ & $11(23.9)$ \\
$25-36$ & $9(19.6)$ \\
$37-48$ & $2(4.3)$ \\
$49-60$ & $2(4.3)$ \\
$>60$ & $5(10.9)$ \\
Total & $46(\sim 100)$
\end{tabular}

All the children were delivered at term. The average age of mothers was 34.1 years and of fathers 37 years. Twelve mothers (26\%) had history of febrile illnesses during pregnancy, 13 mothers $(28.3 \%)$ had history of use of herbal medications during pregnancy.

Using Swanson's classification of congenital limb anomalies $(8,9)$, the most common subgroup encountered was failure of differentiation (58.4\%), next was duplications (26\%) (Table 2).

Table 2. Frequency of cases based on Swanson's classification

\begin{tabular}{lc}
\hline Class & Frequency $(\%)$ \\
\hline Failure of formation & $6(11.32)$ \\
$\quad$ longitudinal & $0(0.00)$ \\
transverse & $31(58.49)$ \\
Failure to differentiate & $1(1.89)$ \\
Overgrowth & $0(0.00)$ \\
Hypoplasia & $14(26.42)$ \\
Duplications & $1(1.89)$ \\
Constriction band syndrome & $0(0.00)$ \\
Generalised skeletal abnormalities & $53(\sim 100)$ \\
Total &
\end{tabular}

Syndactyly was the most common individual descriptive diagnosis observed; it was present in 26 (49\%) diagnosis cases: 22 separately and 4 in combination with polydactyly. Next was polydactyly at 14 (26.4\%) cases: 10 separately and 4 in combination with syndactyly (Table 3).

Eleven patients had other associated syndromic anomalies affecting other body systems and the musculoskeletal system: 
- tibial hemimelia in a patient with syndactyly

- poorly formed ear lobes (pinnae) in a patient with syndactyly

- left congenital talipes equino-varus deformity in a patient with clinodactyly

- proximal focal femoral deficiency and big toe duplication in a patient with radial deficiency

- anorectal malformation in a patient with radial deficiency

- syndactyly of the feet in a patient with radial deficiency
- associated lower limb constriction bands in a patient with bilateral upper limb constriction bands

- foot polydactyly in a patient with radial deficiency

- syndactyly in a patient with other features of Apert's syndrome and anemia

- radial deficiency with atrial septal defect in patient with Holt-Oram's syndrome

- thrombocytopenia with in a patient with radial deficiency

Table 3. Frequency distribution by individual diagnosis, other associated anomalies and complications of treatment

\begin{tabular}{|c|c|c|c|}
\hline Diagnosis & Frequency (\%) & Other associated anomalies & Complications of treatment \\
\hline \multicolumn{4}{|l|}{ Syndactyly } \\
\hline Simple & $16(30.19)$ & Tibia hemimelia & Wound infections (5) \\
\hline Complex & $6(11.32)$ & $\begin{array}{l}\text { Poorly formed Pinnae } \\
\text { Apert's syndrome }\end{array}$ & Skin flap necrosis (4) \\
\hline \multicolumn{4}{|l|}{ Polydactyly } \\
\hline Pre-axial & $5(9.43)$ & & \\
\hline Post-axial & $2(3.77)$ & & \\
\hline Central & $3(5.66)$ & & \\
\hline \multirow[t]{2}{*}{ Radial club hand } & $5(9.43)$ & *PFFD & Ilizarov pin tract infections \\
\hline & & $\begin{array}{l}\text { Anorectal malformation } \\
\text { Duplicate halux } \\
\text { Feet syndactyly } \\
\text { Foot polydactyly } \\
\text { Thrombocytopenia } \\
\text { Holt-Oram's syndrome }\end{array}$ & $\begin{array}{l}\text { Recurrence (postmanipulative cast } \\
\text { treatment }(2)\end{array}$ \\
\hline Polysyndactyly & $4(7.55)$ & & \\
\hline Clinodactyly & $3(5.66)$ & ${ }^{+}$Left CTEV & \\
\hline Camptodactyly & $3(5.66)$ & & \\
\hline \multicolumn{4}{|l|}{ Cleft hand } \\
\hline Typical & $1(1.89)$ & & \\
\hline Atypical & $1(1.89)$ & & \\
\hline $\begin{array}{l}\text { Congenital pseudoarthrosis } \\
\text { (clavicle) }\end{array}$ & $1(1.89)$ & & \\
\hline Constriction bands (bilateral) & $1(1.89)$ & $\begin{array}{l}\text { Bilateral Lower limb } \\
\text { Constriction bands }\end{array}$ & \\
\hline Thumb hypoplasia & $1(1.89)$ & & \\
\hline Bifid humerus & $1(1.89)$ & & \\
\hline Total & $53(\sim 100 \%)$ & & \\
\hline
\end{tabular}

Treatments offered included soft tissue release and skin grafting+osteotomies for simple and complex syndactyly respectively, excision/amputation for polydactyly, serial manipulation and casting for two of the radial club hand patients with Bayne's type 1 and 2. Ilizarov external fixator was used for lengthening bone and correcting deformity for three other patients who had Bayne's type 4 radial club hands. The Holt-Oram syndrome was initially referred for cardiac surgery before coming back for deformity correction. In addition, soft tissue release and osteotomy were done for clinodactyly, soft tissue release for constriction bands, while cleft hand patients were counseled and left alone. Seven patients refused treatment.

Figures 1a-c shows an 8-year-old boy who had right radial club hand with associated cardiac septal defect before, during and after treatment with Ilizarov device.

Figures $2 \mathrm{a}$ and $2 \mathrm{~b}$ show a child who had right complete simple syndactyly of the middle and ring fingers (preand postoperative). 
Complications included five cases of wound infection and four of skin flap necrosis (during treatment of syndactyly). Pin tract infections occurred in two patients while using the Ilizarov device, which necessitated use of antibiotics in addition to local pin tract care on two occasions. Two patients with radial club hands treated with serial manipulation and casting came back with recurrence of deformity and had remanipulation.

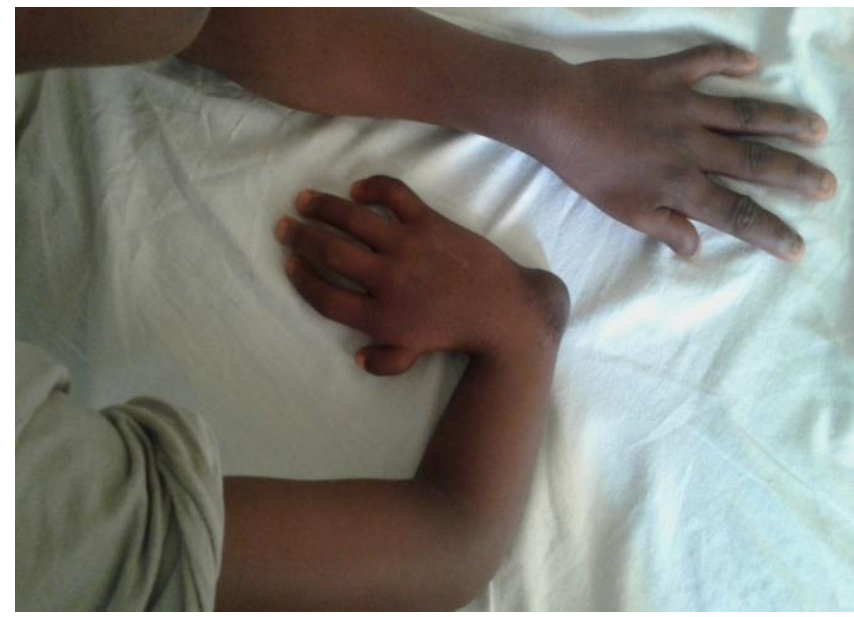

Figure 1a. Right radial club hand, bilateral thumb hypoplasia and cardiac septal defect (Holt-Oram syndrome).

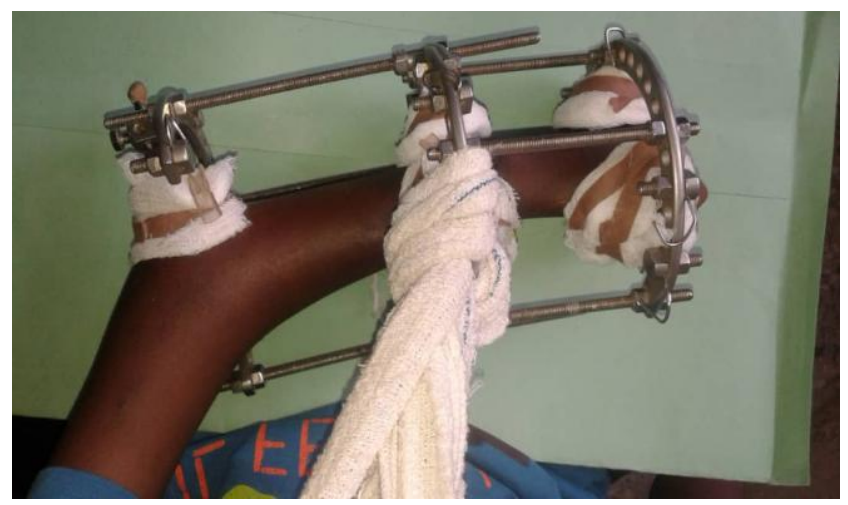

Figure 1b. Ilizarov external fixator applied to right upper limb to lengthen bone and correct deformity.

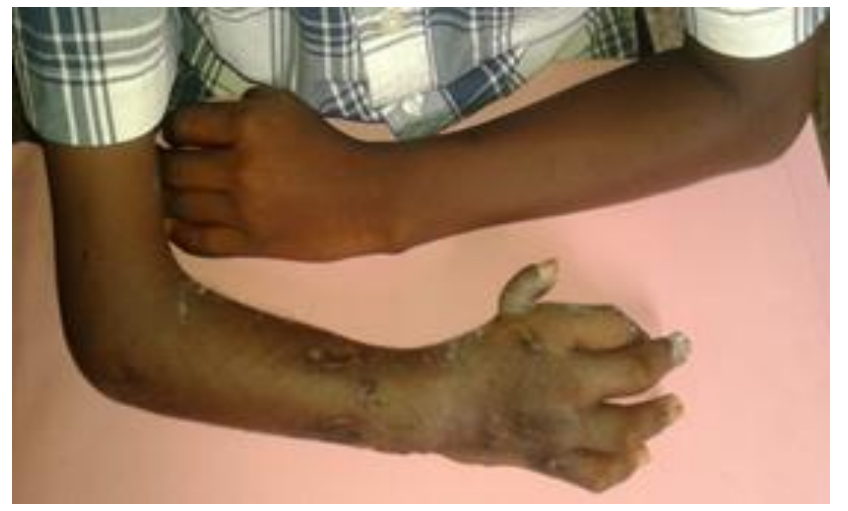

Figure 1c. After correction.

\section{Discussion}

Congenital anomalies of the upper limbs are not rare, and the practicing orthopedic surgeon should be able to diagnose common anomalies when they present, initiate appropriate evaluation/investigations to detect any associated systemic conditions as necessary, and refer when indicated (5).

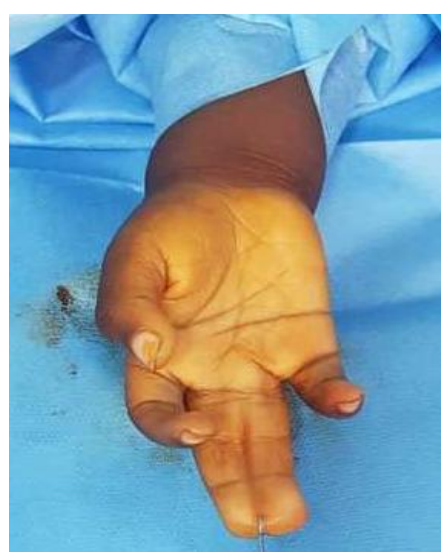

Figure 2a. Complete simple syndactyly of the ring and middle fingers.

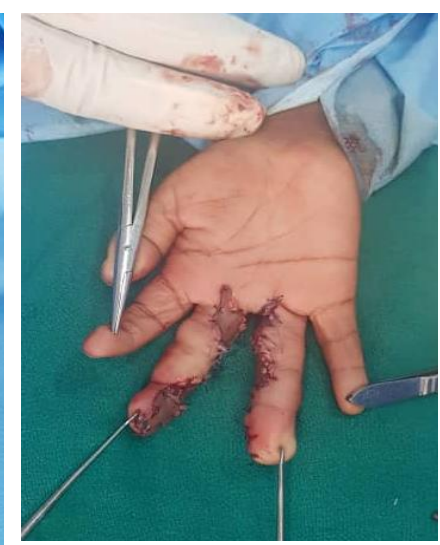

Figure 2b. After soft tissue release and full thickness skin graft.
In treating children with congenital upper limb anomalies, considerations may include whether or not to treat surgically, age at presentation, surgical options, and probable cosmetic and functional outcomes. In addition, psychological and emotional dispositions of the parents, who may have a sense of guilt, including that of the matured child who may be a source of mockery at school, are all important considerations $(2,5)$.

The age at surgical treatment is important in the functional outcome of patients with congenital upper extremity anomalies. In the first year of life, there is greater cerebral plasticity and such deformities that need correction, bearing other considerations in mind, should be surgically done as early as possible as the child will adapt functionally better (10).

Early presentation cannot be overemphasized. In this study, only $37 \%$ of patients presented to us within the first 12 months of life. Mba et al. (7) in a 10-year review of congenital anomalies of the hand in their center in Enugu, Nigeria, reported that almost half $(48.8 \%)$ of their cases presented within 12 months of life. A worse scenario has been recorded by Goswami et al. (1) from a hospital in Pakistan where only 4 (13.3\%) out of 30 cases presented within 12 months of life. Poverty, ignorance and activities of unorthodox practitioners are some of the reasons for this late presentation in developing countries (7) compared with developed and enlightened societies where early presentation is the norm. 
Sex ratios in studies of congenital anomalies of the upper extremities vary from study to study, except for specific diagnoses like syndactyly in which males have been reported to be two times more affected than females $(7,11)$.

The present study had more males than females (1.6:1). Similarly, Koskimies et al. (12) found more males [234] affected than females [185] in their study (1.26:1). In contrast, Mba et al. (7) and Goswami et al. (1) observed a preponderance of females in their studies, with male: female ratios of 1:1.69 and 1:1.5 respectively, similar to what Giele et al. (13) recorded. Equal sex ratio of 1:1 has been reported by Golfarb et al. (14).

Some congenital anomalies have been noted to increase in frequency with increased parental age. Giele et al. (13) noted that congenital upper limb anomalies are more common in babies of older mothers. The average maternal age in this study was 34 years. This is higher than the average of 31 years reported by Mba et al. (7).

The teratogenic effects of hyperthermia in pregnant animals and humans have been recognized and widely reported in the literature $(4,7,15-17)$. The degree of teratogenicity is said to depend on the degree of increased temperature, the duration of exposure, and the gestational age of the mother $(16,18)$. Twelve mothers (26\%) had positive history of febrile illnesses during pregnancy in this study. Mba et al. (7) similarly reported that $26 \%$ of mothers in their study had febrile illnesses during the index pregnancies. Various etiological factors might be responsible for these febrile conditions, with malaria being a leading cause in our environment $(7,19)$.

The use of herbal products during pregnancy and lactation is a common practice in Africa and many parts of the world. These products are however not entirely risk-free to the developing embryo $(7,19,20)$. Over $28 \%$ of mothers in this study admitted using herbal products during pregnancy. A study from South Africa involving 229 pregnant women revealed that $55 \%$ used herbal products (21). Another study from Nigeria (7) recorded that $11.6 \%$ of mothers of children with congenital hand anomalies had used herbal products during pregnancy. While a direct cause-effect relationship between these products and congenital upper limb anomalies has not been established, mothers should be more discrete with the type of products they ingest during pregnancy.

All the children reviewed in this study were delivered at term. However, Giele et al. (13) in a population-based study in Australia reported that congenital anomalies of the upper limbs are more common in pre-term babies.
Various classification systems for congenital anomalies of the extremities have been put forward $(3,8,9,13,21)$. Swanson's classification $(8,9)$ has been used here to group the patients into 7 groups, in addition to individual descriptive anatomic diagnosis used in managing individual patients. Over $58 \%$ of diagnoses in this study fell under failure of differentiation (group 2). In another hospital-based study from Pakistan, Goswami et al. (1) similarly recorded that $53.8 \%$ of the cases in their study also belonged to the group of failure of differentiation. In addition, Giele et al. (13) also reported that failure of differentiation was the commonest category found in their study, making up 35\% of the total-though a much lower proportion than seen in this and Goswami et al.'s studies.

Jordan et al. (11) opined that syndactyly is the most common congenital defect of the hand. About $49 \%$ of patients in this study presented with syndactyly (either isolated or combined with other diagnosis), making it the commonest finding in this and in Goswami et al. (1) and Mba et al.'s (7) studies.

Congenital anomalies of the upper limb may be associated with other anomalies of the cardiovascular, neurologic, craniofacial and other systems including VATER/VACTERL associations and syndromes $(1,2,4)$. These associations make it imperative that every presenting child be examined in detail and investigations done when indicated, with appropriate referrals and multidisciplinary management as necessary. In this study, about $24 \%$ of patients also had congenital anomalies affecting either the lower limbs or other systems, including cases of Holt-Oram, Apert's and TAR (thrombocytopenia absent radius) syndromes. Similarly, Goswami et al. (1) in their series of 30 cases of congenital upper limb anomalies found 4 cases of associated constriction bands and 3 cases of Apert's syndrome (about 23\% in all). However, Froster and Braid (23) observed that the proportion of children with upper limb deficiencies that has abnormalities elsewhere in the body varied with the subgroup of specific diagnosis. They reported that $89 \%$ of cases of longitudinal radial deficiencies in their study had associated anomalies elsewhere in the body while only $28 \%$ of those with transverse radial deficiencies had additional malformations.

Treatment of children with congenital upper extremity anomalies can be challenging due to their diverse nature, but also rewarding as it provides an opportunity for the surgeon to positively impact the child's growth and development (3). Treatment, which is multidisciplinary in many instances involving the pediatrician, occupational 
and physical therapist, pediatric cardiologist, hematologist, neurosurgeon etc., is individualized and is aimed at getting a good upper limb function and cosmetic outlook. (7,24) Furthermore, other important considerations will include the actual diagnosis and severity of condition in a particular child, other associated systemic defects, functional demands of the child, age at presentation, surgical expertise, facilities available to the surgeon and, very importantly, in our environment the financial status of the parents or guardian. Our patients were offered the best available cost-effective treatments for their conditions.

Cases of syndactyly, the most commonly encountered anomaly in this study, had soft tissue releases with Zplasties and full thickness skin grafts for simple cases, as similarly described in other studies $(7,12,24)$, with additional osteotomies in complex cases. In cases of polydactyly, the least functional or least developed fingers were excised or amputated, as also reported by other authors $(2,3,7)$.

The use of external fixators in the treatment of radial club hand, especially Bayne's types III and IV, has been variously described in literature (2,25-27). Three of our patients with Bayne's type IV absent radius were treated with Ilizarov frame application to lengthen the bone and correct the deformity.

\section{Conclusion}

Congenital upper limb anomalies present as a variety of diagnostic entities in our setting. Syndactyly was the commonest finding in this study, next was polydactyly. Appropriate individualized treatments were offered according to diagnosis.

\section{References}

1. Goswami P, Kumar M, Effendi S. Frequency and variation of congenital anomalies of the upper limb at Liaquat University Hospital, Jamshoro. Int. J Sci Basic Appl Res (IJSBAR). 2014;17(2):275-282.

2. Kozin SH. Upper Extremity Congenital Anomalies. J Bone Joint Surg (Am). 2003;85:1564-1576.

3. Chung MS. Congenital differences of the upper extremity: Classification and treatment principles. Clin Orthop Surg. 2011; 3(3):172-177.

4. Gallant GG, Bora EW. Congenital deformities of the upper extremity. J Am Acad Orthop Surg. 1996; 4:162-171.

5. Dy JC, Swarup I, Daluiski A. Embryology, diagnosis and evaluation of congenital hand anomalies. Curr Rev Muskuloskelet Med. 2014;7(1):60-67.

6. Binesto ENF. Congenital deformities of the upper limb, part II: failure of formation and duplications. Res Bras Ortop. 2013;48(1):1-3.

7. Mba UC, Ogbonnaya IS, Onah II. Analysis of congenital hand anomalies at a specialist hospital in a developing country. The Internet Journal of Hand Surgery. 2017;8(1).
8. Swanson AB. A classification for congenital limb malformations. J Hand Surg (Am). 1976;1(1):8-22.

9. Swanson AB, Swanson GD, Tada K. A classification for congenital limb malformations. J Hand Surg. 1983;8(5):693702.

10. Bisneto ENF. Congenital deformities of the upper limbs. Rev Bras Ortop. 2012;47(5):545-552.

11. Jordan D, Hindocha S, Dhital M, et al. The epidemiology, genetics and future management of syndactyly. Open Orthop J. 2012;6(suppl 1:M2):14-27.

12. Koskimies E, Lindfors N, Gissl er M, et al. Congenital upper limb deficiencies and associated malformations in Finland: A population-based study. J Hand Surg (Am). 2011;36(6):10581065.

13. Giele H, Gieke C, Bower C, et al. The incidence and epidemiology of congenital upper limb anomalies: A total population study. J Hand Surg. 2001;26A:628-634.

14. Golfarb CA, Wall LB, Bohn DC, et al. Epidemiology of congenital upper limb anomalies in a mid-west United States population: An assessment using Oberg, Manske and Tonkin Classification. J Hand Surg (Am). 2015;40:127-132.

15. Graham JM, Edwards MJ, Edwards MJ. Teratogen Update: gestational effects of maternal hyperthermia due to febrile illness and resultant patterns of defects in humans. Teratology. 1998;58:209-221.

16. Hande P, Veena K. Teratogenic effect of hyperthermia during early organogenesis period in mice. Teratog Carcinog Mutagen. 1993;13:145-150.

17. Graham JM, Edwards MJ. Teratogenic effects of maternal hyperthermia. Ann Res Inst Environ Med. 1989;40:365-374.

18. Edwards MJ. Hyperthermia as a teratogen: A review of experimental studies and their clinical significance. Teratog Carcinog Mutagen. 1986;6:563-582.

19. Aduloju AP. Effect of intermittent preventive treatment of malaria on the outcome of pregnancy among women attending antenatal clinic of a new Nigerian teaching hospital. Nig Med J. 2013;54:170-175.

20. Ernst E. Herbal medicinal products during pregnancy: Are they safe? BJOG. 2002;109(3):227-35.

21. Mabina MH, Pitsoe SB, Moodley J. The effects of traditional herbal medicines on pregnancy outcome. S Afr Med J. 1997;87:1008-1010.

22. Day HJB. The ISO/ISPO classification of congenital limb deficiency. Prosthet Orthot Int. 1991;15:67-69.

23. Foster UG, Baird PA. Upper limb deficiencies and associated malformations: A population-based study. Am J Genet. 1992;44(6):767-781.

24. Watson S. The principles of management of congenital anomalies of the upper limb. Arch Dis Child. 2000;83:10-17.

25. Peterson BM, McCarroll HR, James MA. Distraction lengthening of the ulna in children with radial longitudinal deficiency. J Hand Surg (Am). 2007;32(9):1402-1407.

26. Cattaneo R, Catagni MA, Guerreschi F. Treatment of radial agenesis with Ilizarov method. Rev Chir Orthop Reparatrice Appar Mot. 2001;87(5):443-450.

27. Bhat SB, Kamath AF, Sehgal K, et al. Multi-axial correction system in the treatment of radial club hand. J Child Orthop. 2009;3(6):493-498. 